\title{
PAPEL DOS RINS NA HIPERTENSÃO ARTERIAL INDUZIDA PELO TRATAMENTO CRÔNICO COM OUABAÍNA EM RATOS
}

Dissertação apresentada ao Instituto de Ciências Biomédicas da Universidade de São Paulo, para obtenção do Título de Mestre em Fisiologia Humana.

Área de Concentração: Fisiologia Humana

Orientadora: Prof. Dr. Luciana Venturini Rossoni 


\section{RESUMO}

Ferreira-Neto HC. Papel dos rins na hipertensão arterial induzida pelo tratamento crônico com ouabaína em ratos [Dissertação (Fisiologia Humana)]. São Paulo: Instituto de Ciências Biomédicas da Universidade de São Paulo; 2009.

Os rins são órgãos que participam da regulação da pressão arterial à longo prazo. A $\mathrm{Na}^{+} \mathrm{K}^{+}$-ATPase (NKA) é uma proteína integral de membrana que participa dos principais mecanismos de transporte ao longo dos túbulos renais gerando o gradiente eletroquímico necessário para a reabsorção de sódio, outros substratos e fluido. Sabe-se que a administração crônica de ouabaína (OUA), um inibidor da NKA, induz hipertensão arterial em ratos Wistar. No entanto, o papel dos rins nesse modelo de hipertensão ainda não está bem elucidado. Desta forma, o objetivo do presente estudo foi avaliar as possíveis alterações na função renal induzidas pelo tratamento crônico com OUA por 5 ou 20 semanas. Para tal, ratos Wistar foram tratados com veículo (CT) ou OUA ( 8,0 $\mu \mathrm{g} / \mathrm{dia}$, subcutaneamente) por 5 e 20 semanas e após os períodos de tratamento os animais foram alocados em gaiolas metabólicas para avaliação da função renal. Sendo assim, foi observado que o tratamento crônico com OUA promoveu hipertensão de mesma magnitude nos dois períodos avaliados (5 semanas: CT $126 \pm 4$ vs OUA $147 \pm 2 \mathrm{mmHg}$; 20 semanas: CT $124 \pm 2$ vs OUA $139 \pm 2 \mathrm{mmHg}$ ), como previamente demonstrado. Além disso, a administração de OUA induziu o aumento da ingestão de água (OUA 5 semanas: 32\%; OUA 20 semanas: 34\%), do fluxo urinário (OUA 5 semanas: 62\%; OUA 20 semanas: $64 \%$ ) e da expressão protéica da isoforma $\alpha_{1}$ da NKA (OUA 5 semanas: 90\%; OUA 20 semanas: 70\%). Porém, o tratamento com OUA não foi capaz de alterar de maneira significativa o ritmo de filtração glomerular, assim como a fração de excreção de $\mathrm{Na}^{+}$e $\mathrm{K}^{+}$. Pode-se concluir que, o tratamento crônico com OUA induz hipertensão leve independente do tempo de sua administração, porém os rins parecem não contribuir de forma importante para o processo hipertensivo neste modelo de hipertensão.

Palavras-chave: Ouabaína; $\mathrm{Na}^{+} \mathrm{K}^{+}$-ATPase; Hipertensão; Função Renal. 


\begin{abstract}
Ferreira-Neto HC. Role of kidneys in ouabain-induced hypertension rats [Master thesis (Human Physiology)]. São Paulo: Instituto de Ciências Biomédicas, Universidade de São Paulo; 2009.

Kidneys are organs that participate of long-term arterial pressure regulation. $\mathrm{Na}^{+} \mathrm{K}^{+}$ATPase (NKA) is an integral protein of the plasma membrane that participates in the major transport mechanisms in the renal tubules providing the electrochemistry gradient for the sodium reabsorption, others substrates and fluid. Chronic administration of ouabain (OUA), a NKA inhibitor, induces hypertension in Wistar rats. However, the role of kidneys in this model of hypertension is not elucidated. In this way, the aim of the present study was evaluate the possibles alterations in renal funtion induced by the chronic treatment with OUA by 5 and 20 weeks. For this, male Wistar rats were treated with vehicle $(\mathrm{CT})$ or OUA $(\sim 8.0 \mu \mathrm{g} / \mathrm{day}$, subcutaneously) during 5 or 20 weeks and after the period of treatment animals were placed in metabolic cages to evaluate renal function. As previously demonstrated, chronic treatment with OUA induced hypertension in a similar magnitude in both experimental groups (5 weeks: CT $126 \pm 4$ vs OUA $147 \pm 2$ mmHg; 20 weeks: CT $124 \pm 2$ vs OUA $139 \pm 2 \mathrm{mmHg}$ ). Moreover, OUA administration was able to increase water intake (OUA 5 weeks: 32\%; OUA 20 weeks: 34\%), urinary flow (OUA 5 weeks: $62 \%$; OUA 20 weeks: $64 \%$ ) and protein expression of $\alpha_{1}$ isoform of NKA (OUA 5 weeks: 90\%; OUA 20 weeks: 70\%). However, OUA treatment did not alter significantly the glomerular filtration rate, likewise the fractional excretion of $\mathrm{Na}^{+}$and $\mathrm{K}^{+}$. In summary, chronic OUA treatment induces mild hypertension independent of the period of administration, but the kidneys don't play an important role in the hypertensive process in this model of hypertension.
\end{abstract}

Keywords: Ouabain; $\mathrm{Na}^{+} \mathrm{K}^{+}$-ATPase; Hypertension; Renal Function. 


\section{INTRODUÇÃO}

As doenças do aparelho cardiovascular representam um importante problema de saúde pública, considerando-se a prevalência crescente e a morbi-mortalidade associada, sendo que a hipertensão arterial é a principal causa para o aumento do risco de desenvolvimento dessas doenças.

Embora muitos manuscritos descrevam a hipertensão arterial nos Estados Unidos e em outros países desenvolvidos, deve ser notado que as doenças cardiovasculares são as principais causas de morte em todo o mundo, com grande destaque em países economicamente desenvolvidos, porém também em países emergentes e em desenvolvimento (Kearney et al., 2005). Segundo o DATASUS (2005) do Ministério da Saúde, as doenças do aparelho circulatório são as maiores causas de mortalidade geral no Brasil (aproximadamente 30\%), e representam $11 \%$ de todas as internações realizadas em hospitais do SUS, sendo importante salientar que a principal causa de internação nos hospitais brasileiros são as doenças cardiovasculares, e entre estas, quadros patológicos decorrentes de complicações devidos à hipertensão arterial, tais como o acidente vascular cerebral e a doença arterial coronariana.

A prevalência da hipertensão arterial aumenta com a idade e a obesidade em ambos os sexos, porém sabe-se que indivíduos negros têm uma tendência maior de apresentar níveis mais elevados de pressão arterial do que indivíduos brancos (Kaplan, 2006).

A classificação da pressão arterial é baseada em três aferições, com o indivíduo sentado, realizadas no consultório médico com intervalo de um minuto entre elas, sendo a média das duas últimas considerada a pressão arterial do indivíduo segundo as Diretrizes Brasileiras de Hipertensão Arterial (2006). Além, disso foram redefinidos os valores de pressão arterial considerando fatores de risco, lesões de órgãos-alvo e doenças associadas (Quadro 1). 


\begin{tabular}{|l|c|c|}
\hline Classificação & $\begin{array}{c}\text { Pressão Sistólica } \\
(\mathrm{mmHg})\end{array}$ & $\begin{array}{c}\text { Pressão Diastólica } \\
(\mathrm{mmHg})\end{array}$ \\
\hline Ótima & $<120$ & $<80$ \\
\hline Normal & $<130$ & $<85$ \\
\hline Limítrofe & $130-139$ & $85-89$ \\
\hline Hipertensão estágio 1 & $140-159$ & $90-99$ \\
\hline Hipertensão estágio 2 & $160-179$ & $100-109$ \\
\hline Hipertensão estágio 3 & $\geq 180$ & $\geq 110$ \\
\hline
\end{tabular}

Quadro 1: Classificação da pressão arterial, retirado e modificado das $\vee$ Diretrizes Brasileiras de Hipertensão Arterial, 2006.

A hipertensão arterial sistêmica é dividida em dois grandes grupos: hipertensão primária e hipertensão secundária. A hipertensão primária caracterizase pela elevada pressão sanguínea na qual causas secundárias não estão presentes (Carretero e Oparil, 2000; Kaplan, 2006).

Apesar de não apresentar uma causa definida, sabe-se que a hipertensão primária é multifatorial, ou seja, diferentes fatores, isolados ou não, podem contribuir para seu desenvolvimento. Dentre os fatores contribuintes para o desenvolvimento da hipertensão primária estão: o caráter hereditário, a alta ingestão de sódio (em pacientes sensíveis ao sal), a retenção renal de sódio, o sistema reninaangiotensina-aldosterona, o sistema nervoso simpático e o estresse, a obesidade, o diabetes, a resistência à insulina, a alta ingestão de álcool, o hábito de fumar, a idade, a raça, a baixa ingestão de potássio, a baixa ingestão de cálcio, entre outros (Kaplan, 2006).

Diferentemente, a hipertensão secundária tem causa conhecida e pode ser prevenida ou remediada. Algumas causas para o desenvolvimento de hipertensão secundária são a doença renal crônica, a isquemia renal (hipertensão renovascular), o aldosteronismo primário, a síndrome de Cushing ou o tratamento crônico com glicocorticóide, entre outras (Kaplan, 2006). No entanto, esta forma de hipertensão acomete cerca de $5 \%$ a $10 \%$ dos pacientes e, portanto, a grande maioria dos pacientes diagnosticados como hipertensos apresentam hipertensão primária.

$O$ fato da hipertensão arterial ser uma enfermidade de origem multifatorial, ter uma elevada prevalência e estar associada à uma gama enorme de doenças levou vários pesquisadores a estudarem os mecanismos associados à essa enfermidade. $\mathrm{Na}$ hipertensão arterial o rim exibe comportamento ambíguo, podendo ao mesmo tempo ser a causa da hipertensão ou sofrer seus efeitos lesivos, o que contribui, à 
medida que a lesão evolui de forma a propiciar a progressão da mesma até quadros de insuficiência renal. Sendo assim, é de grande relevância estudar os mecanismos renais envolvidos nesta doença.

\subsection{Os rins e a regulação da pressão arterial}

A regulação da pressão arterial é um processo complexo e depende de vários mecanismos atuando em paralelo, cada um com sua própria dinâmica e com seus próprios efetores. Há mecanismos de ação rápida, como os barorreceptores, os quimiorreceptores arteriais e a resposta isquêmica do sistema nervoso central, capazes de responder em segundos a variações bruscas da hemodinâmica circulatória (Guyenet, 2006). Sabe-se também que existe mecanismos capazes de regular a pressão arterial a médio prazo. Nesse sentido, Coleman e Guyton (1969) demonstraram que durante o processo de desenvolvimento da hipertensão induzida por sobrecarga salina ocorre, a médio prazo, aumento da resistência periférica total.

A regulação em longo prazo da pressão arterial está intimamente associada com a homeostase do volume do fluido extracelular, o qual por sua vez é determinado pelo conteúdo de sódio. O balanço de sódio, isto é, o equilíbrio entre o que é ingerido e o que é eliminado, é crítico para o volume do fluido extracelular, e os rins, como a principal rota através da qual o sódio é eliminado do corpo, são fundamentais para a estabilidade da pressão arterial a longo prazo (Mullins et al., 2006). Sendo assim, uma elevação da pressão arterial ou da pressão de perfusão na artéria renal resulta em um rápido aumento da excreção renal de água e sódio pelos rins, denominada natriurese pressórica. Com isso, cai o débito cardíaco, baixando a pressão arterial e retomando a taxa de excreção renal de sódio ao nível basal (Zatz, 2002).

Guyton e Coleman demonstraram em 1967 que os rins têm importância primária na regulação da pressão arterial. Eles observaram que uma vasoconstrição sistêmica não poderia induzir aumentos sustentados na pressão arterial se a função renal estivesse normal (Guyton e Coleman, 1967). Sendo assim, a função renal alterada poderia contribuir para a elevação da pressão arterial ou mesmo fazer com que os níveis de pressão arterial não retornassem a valores normais após um aumento sustentado da mesma. Nesse sentido, tem-se que a hipertensão arterial pode resultar de uma redução da capacidade de eliminar sódio em resposta ao 
aumento da ingestão ou da falta de habilidade dos rins em promover natriurese pressórica (Mullins et al., 2006).

As causas que levam ao prejuízo da função natriurética renal em muitas formas de hipertensão arterial são facilmente identificadas: perda de massa renal funcional ou estenose da artéria renal. Estes fatores podem levar à redução da excreção de sódio e, consequentemente, o aumento do risco de desenvolver hipertensão. Clinicamente, há frequentemente um ciclo vicioso: a hipertensão arterial causa dano renal, o qual causa mais hipertensão (Kaplan, 2006).

Os rins respondem a uma série de compostos vasoativos, como as prostaglandinas, o óxido nítrico, sistema renina-angiotensina-aldosterona (SRAA), entre outros. O SRAA é um dos mais potentes sistemas vasoativos e tem papel crítico na regulação da pressão arterial e na homeostase do sódio, compreendendo desde a ação vasoativa da angiotensina II (Ang II) até a estimulação da zona fasciculada da glândula adrenal para a síntese e liberação do mineralocorticóide aldosterona (Kobori et al., 2007). A Ang II é um dos mais potentes hormônios responsáveis pela retenção de sódio no corpo. As ações intrarenais diretas da Ang II que contribuem para aumentar a reabsorção tubular são complexas, incluindo constrição das arteríolas glomerulares, o que altera a dinâmica capilar peritubular e o fluxo sanguíneo medular renal, e ações diretas no transporte realizado por células epiteliais tubulares (Kobori et al., 2007). No túbulo proximal, local onde ocorre cerca de $70 \%$ da reabsorção de sódio, a Ang II estimula a reabsorção de fluido por aumentar o transporte transcelular de sódio e bicarbonato via ativação do trocador $\mathrm{Na}^{+} / \mathrm{H}^{+}$na membrana apical e do cotransporte $\mathrm{Na}^{+}-\mathrm{HCO}_{3}{ }^{-}$e da $\mathrm{Na}^{+} / \mathrm{K}^{+}-$ATPase na membrana basolateral e via inserção $\mathrm{H}^{+}$-ATPase na membrana apical (Liu e Cogan, 1988; Garvin, 1991; Mitchell et al., 1992; Eiam-Ong et al., 1993; Wang e Giebisch, 1996). Já a aldosterona atua principalmente nas células principais dos ductos coletores onde estimula o aumento da densidade de canais para $\mathrm{Na}^{+}$e $\mathrm{K}^{+}$na membrana luminal e a atividade da $\mathrm{Na}^{+} \mathrm{K}^{+}$-ATPase basolateral (Kobori et al., 2007). Dessa maneira, a aldosterona promove a retenção de cloreto de sódio e secreção de potássio nas células principais dos ductos coletores corticais (Kobori et al., 2007). 


\subsection{Papel dos rins em modelos experimentais de hipertensão arterial}

O papel dos rins tem sido estudado em diversos modelos experimentais de hipertensão arterial há muito tempo e uma vasta literatura científica foi produzida. $A$ participação dos rins no processo hipertensivo foi evidenciada principalmente através de estudos de transplante-cruzado de rins de animais geneticamente hipertensos e seus controles normotensos, e observou-se que a pressão arterial nos animais transplantados refletia as características genéticas dos doadores ao invés das características dos transplantados (Kopf et al., 1993). Porém, os mecanismos renais responsáveis pelo desenvolvimento da hipertensão em diversos modelos experimentais também foram estudados e é de suma importância conhecê-los para avaliar a participação desse órgão nos diferentes modelos de hipertensão arterial.

Sabe-se que ratos espontaneamente hipertensos (SHR) desenvolvem hipertensão severa e que os rins têm participação importante nesse processo. Beierwaltes et al. (1982) mostraram que SHR jovens (3 a 8 semanas de idade) desenvolvem hipertensão por reterem mais sódio e água do que os normotensos da mesma idade. Porém, estes animais na fase adulta (11 a 13 semanas de idade) apresentam similaridade na reabsorção de fluido pelos rins nos diversos segmentos do néfron quando comparados com normotensos (Arendshorst e Beierwaltes, 1979). Sendo assim, estes pesquisadores sugeriram que diferenças determinadas geneticamente no padrão de excreção renal devem ser responsáveis ou pelo menos contribuir para elevar a pressão arterial em SHR jovens (Beierwaltes et al., 1982), porém na idade adulta os rins de animais geneticamente hipertensos requerem uma pressão arterial maior para excretar uma dada quantidade de sal e água do que rins de animais normotensos (Arendshorst e Beierwaltes, 1979). Outra observação importante é o fato de SHR jovens apresentarem aumento da resistência vascular renal acompanhado de redução do ritmo de filtração glomerular, o que pode contribuir para o início do processo hipertensivo (Dilley et al., 1984). Além dos fatores acima descritos que contribuem para o início e manutenção da hipertensão em animais SHR, soma-se a atividade aumentada da $\mathrm{Na}^{+} \mathrm{K}^{+}$-ATPase no túbulo proximal (Garg et al., 1985) assim como do trocador $\mathrm{Na}^{+} / \mathrm{H}^{+}$(Morduchowicz et al., 1989).

Cabe ressaltar que os nervos simpáticos renais têm papel importante no processo de reabsorção de sódio e água pelos túbulos renais. Nesse sentido, Slick 
et al. (1975) demonstraram que a estimulação aguda dos nervos simpáticos renais de cães reduz a excreção absoluta de sódio e; Bello-Reuss et al. (1976) observaram que a estimulação elétrica de baixa frequência nos nervos simpáticos renais em ratos induz resposta antidiurética e antinatriurética e, que este efeito resulta do aumento da reabsorção de água e sódio pelo túbulo proximal. Em SHR já foi documentado que a atividade simpática do nervo renal é aumentada (Okamoto et al., 1967; Judy et al., 1976, 1979; Thorén e Ricksten, 1979) e que a desnervação renal nesses animais retarda o desenvolvimento da hipertensão devido ao aumento da excreção de sódio (Winternitz et al., 1980).

Diante da elevada prevalência da hipertensão, das anormalidades que podem conduzir ao seu desenvolvimento e do papel renal na regulação a longo prazo da pressão arterial fez-se necessário estudar a participação dos rins em outros modelos de hipertensão. Sendo assim, a função renal também foi estudada na hipertensão induzida por mineralocorticóide, onde o processo hipertensivo é desencadeado pela administração do mineralocorticóide acetato de deoxicorticosterona (DOCA) e solução salina a 1\% (modelo DOCA-Sal). Os mineralocorticóides tais como a aldosterona ou DOCA tem dois efeitos complementares no metabolismo do sódio: aumentam o apetite por sódio e, simultaneamente, aumentam a reabsorção de sódio nos segmentos distais dos túbulos renais. Isto resulta em retenção de sódio, com conseqüente expansão do volume do fluido extracelular. Os animais DOCA-Sal também são um modelo hipertensão arterial severa e apresentam redução do ritmo de filtração glomerular e do fluxo sanguíneo renal com aumento da resistência vascular renal, do fluxo urinário, da excreção urinária de sódio e da ingestão de solução salina quando comparados com animais que ingerem apenas água (Roman et al., 1988; Kohzuki et al., 1989; Matsumura et al., 1997; Allcock et al., 1998; Pollock et al., 2000a), além de proteinúria e albuminúria (Elmarakby et al., 2008; Wang et al., 2008; Jadhav et al., 2009). Essas alterações são acompanhadas de mudanças estruturais no tecido renal como lesões glomerulares, tubulointersticial e vasculares, além de fibrose e proliferação celular associada com hipertrofia renal (Wang et al., 2008; Jadhav et al., 2009).

A estenose da artéria renal também é uma das causas da hipertensão arterial e, em 1934, Goldblatt e colaboradores demonstraram que poderia ser produzida hipertensão crônica experimentalmente em animais pela constrição das artérias renais com grampos ou clipes de prata ajustáveis. Uma das formas mais comuns de 
produzir hipertensão renal em animais experimentais é por meio da constrição parcial de uma artéria renal enquanto o fluxo sanguíneo para o outro rim permanece intacto (modelo de hipertensão dois rins, um clipe - 2R-1C) (Radzialowski, 1982). Após a realização da cirurgia para a colocação do clipe os animais podem desenvolver hipertensão moderada ou severa (Leenen e Jong, 1971), acompanhada de redução do ritmo de filtração glomerular, albuminúria, glomeruloesclerose, lesões vasculares e tubulointersticiais (Rostand et al., 1982; Himmelstein e Klotman, 1989; Véniant et al., 1994; Kassab et al., 2001; Welch et al., 2003; Wenzel et al., 2003). Além disso, ratos 2R-1C apresentam aumento do apetite pelo sódio (Möhring et al., 1975a) e retenção de sódio (Möhring et al., 1975b), o que sugere que os mecanismos fisiológicos responsáveis pela mudança na homeostase de fluido e eletrólitos são importantes mecanismos causais da hipertensão renal (Radzialowski, 1982).

Além dos compostos vasoativos citados anteriormente, de Wardener et al. (1961) demonstraram um aumento da natriurese após a transfusão de sangue de cães que receberam agudamente infusão de salina para cães controle, sendo que esta natriurese era independente da inervação renal, do ritmo de filtração glomerular, da pressão de perfusão renal ou do fluxo sanguíneo renal (de Wardener et al., 1961). Desta forma, este trabalho sugeria a presença de um fator na circulação após a expansão aguda de volume que induzia um aumento da excreção de sódio. Em 1969, Dahl et al. foram os primeiros a propor que uma substância salurética circulante poderia causar um aumento sustentado na pressão arterial em ratos hipertensos sensíveis ao sal. No mesmo ano, Kramer et al., e em 1970, Buckalew et al., sugeriram que este fator seria um inibidor da $\mathrm{Na}^{+} \mathrm{K}^{+}$-ATPase. Haddy e Overbeck (1976) propuseram que esse fator inibidor da $\mathrm{Na}^{+} \mathrm{K}^{+}$-ATPase poderia exercer um papel importante na gênese da hipertensão nos modelos experimentais de hipertensão dependentes de volume. Por sua vez, em 1982, Hamlyn et al. demonstraram pela primeira vez que este fator inibidor também estava presente na circulação humana e em 1991 este mesmo grupo identificou e purificou essa substância a qual foi caracterizada como ouabaína-endógena (Bova et al., 1991).

Em mamíferos, a ouabaína está presente no plasma em concentrações pico e nanomolares, cuja produção concentra-se na zona glomerulosa do córtex da glândula supra-renal (Ludens et al., 1992; Laredo et al., 1997), no hipotálamo (de Wardener e Clarson, 1985) e na região anteroventral do terceiro ventrículo (AV3V) 
(Pamnani et al., 1981; Songu-Mize et al., 1982). Os principais estímulos para a secreção de ouabaína são: o aumento da concentração plasmática de sódio e volume extracelular (de Wardener et al., 1961; Blaustein, 1993), a Ang II e o ACTH (Laredo et al., 1997).

Já foi demonstrado que os níveis plasmáticos de ouabaína estão aumentados (30-200\%) em muitas formas de hipertensão, incluindo a hipertensão essencial (Argento et al., 1991; Schaeffer et al., 1991; Manunta et al., 1992; Naruse et al., 1994, Manunta et al., 1999; Lanzani et al., 2005; Manunta et al., 2008; Tripodi et al., 2009). Além do mais, análises de regressão múltipla, em pacientes normotensos e hipertensos, revelaram uma significante relação entre pressão sanguínea, índice de massa corporal, idade e os níveis da ouabaína endógena circulantes, porém nenhum dos parâmetros exibia alguma associação com renina ou aldosterona plasmática aumentadas (Rossi et al., 1995). Corroborando os resultados de Rossi et al. (1995), Manunta et al. (1999) demonstraram uma forte correlação positiva entre níveis plasmáticos elevados de ouabaína endógena, pressão diastólica e aumento da massa do ventrículo esquerdo em pacientes com hipertensão essencial. Mais recentemente, esse mesmo grupo (Manunta et al., 2008) demonstrou em pacientes com hipertensão primária que concentrações plasmáticas elevadas de ouabaína (acima de 337 pM) correlacionavam-se com aumento da pressão arterial diastólica, com aumento da concentração de sódio plasmática e com redução da fração de excreção de lítio.

Classicamente, os efeitos da ouabaína são explicados pela sua capacidade de inibir a atividade da bomba de sódio e potássio (Skou e Esmann, 1992; Lingrel, 1992), sendo que sua estrutura foi recentemente elaborada por cristalização (Morth et al., 2007). A Na+K $\mathrm{K}^{+}$-ATPase está presente na maioria das células eucarióticas, é uma proteína integral de membrana e acopla a hidrólise do ATP ao transporte de sódio e potássio através da membrana plasmática e, dessa forma, gera o gradiente eletroquímico para o $\mathrm{Na}^{+}$e o $\mathrm{K}^{+}$através das membranas das células animais. Esse gradiente é necessário para a excitabilidade elétrica, captação celular de íons, nutrientes e neurotransmissores, e regulação do volume celular e $\mathrm{pH}$ intracelular (Sweadner, 1989; Skou e Esmann, 1992; Morth et al., 2007). A Na ${ }^{+} \mathrm{K}^{+}-\mathrm{ATP}$ ase é formada por três subunidades distintas: $\alpha$, com aproximadamente 113 kDa; $\beta$, com aproximadamente 55 kDa; Y, com aproximadamente 14 kDa (Sweadner, 1989; Blanco e Mercer, 1998). 
A subunidade $\alpha$ apresenta quatro isoformas $\left(\alpha_{1}, \alpha_{2}, \alpha_{3}\right.$ e $\left.\alpha_{4}\right)$ e é responsável pela atividade catalítica dessa enzima, possuindo sítios de ligação para os íons $\mathrm{Na}^{+}$ e $\mathrm{K}^{+}$, para o ATP e para os compostos digitálicos, como a ouabaína (Blanco e Mercer, 1998). Estas isoformas diferem pouco quanto ao seu peso molecular, e são diferentes em relação à sensibilidade pelos compostos digitálicos em roedores, sendo que a subunidade $\alpha_{3}$ é a mais sensível, seguida da $\alpha_{2}$, e por fim a $\alpha_{1}$ (Blanco e Mercer, 1998). Foi descrito que os túbulos renais possuem, predominantemente, a subunidade $\alpha_{1}$ da $\mathrm{Na}^{+} \mathrm{K}^{+}$-ATPase (Lingrel, 1992). Nesse sentido, a isoforma $\alpha_{1}$ é a responsável pelo transporte de $\mathrm{Na}^{+}$e $\mathrm{K}^{+}$através da membrana basolateral nos túbulos renais contra seus respectivos gradientes e gera um gradiente eletroquímico necessário para a reabsorção de nutrientes no epitélio renal, sendo esta a principal força para a manutenção do balanço de eletrólitos e fluidos no nível corporal (Féraille e Doucet, 2001). Recentemente, Loreaux et al. (2008) demonstraram que a resposta natriurética após sobrecarga salina é dependente da sensibilidade da isoforma $\alpha_{1}$ da $\mathrm{Na}^{+} \mathrm{K}^{+}$-ATPase. Estes pesquisadores desenvolveram camundongos que apresentavam a isoforma $\alpha_{1}$ da $\mathrm{Na}^{+} \mathrm{K}^{+}$-ATPase sensível à ouabaína, e demonstraram que após uma sobrecarga salina e infusão de ouabaína estes animais tinham aumento da resposta natriurética quando comparados com animais selvagens que apresentavam a isoforma $\alpha_{1}$ da $\mathrm{Na}^{+} \mathrm{K}^{+}$-ATPase resistente à ouabaína.

Até pouco tempo atrás a subunidade $\beta$ era considerada apenas estruturalmente importante, em particular, para a correta expressão da $\mathrm{Na}^{+} \mathrm{K}^{+}$ATPase na membrana (Gerring, 1991; Mercer, 1993). No entanto, hoje já se têm evidências que demonstram um papel funcional da subunidade $\beta$, de uma maneira isoforma-específica, para determinar algumas propriedades catalíticas e de transporte da enzima (Blanco e Mercer, 1998). A isoforma $\beta_{1}$ é expressa de maneira predominante nos rins (Therien et al., 1996). Além disso, sabe-se que a ouabaína é capaz de aumentar a expressão da isoforma $\beta_{1}$ em cultura de cardiomiócitos de ratos neonatos (Kometiani et al., 2000).

A $\mathrm{Na}^{+} \mathrm{K}^{+}$-ATPase também está associada com a subunidade $\mathrm{Y}$. Sabe-se que esta proteína está ausente na maioria das preparações de $\mathrm{Na}^{+} \mathrm{K}^{+}$-ATPase, mas é frequentemente encontrada em preparações de tecido renal (Cortes et al., 2006). No rim é possível encontrar isoformas da subunidade $\gamma$, como a ya e $\gamma b$, além da CHIF (do inglês, fator induzido por hormônio corticosteróide) (Lindzen et al., 2005). Tem sido demonstrado que a subunidade $\mathrm{Y}$ pode atuar como reguladora da $\mathrm{Na}^{+} \mathrm{K}^{+}-$ 
ATPase, influenciando na afinidade pelos íons $\mathrm{Na}^{+}$e $\mathrm{K}^{+}$e pelo ATP. No entanto, já foi descrito que a expressão da subunidade $\mathrm{y}$ não é observada em todos os segmentos do néfron de mamíferos. Desta forma, foi observada a expressão protéica da isoforma ya em segmentos da alça de Henle e em células intercalares do ducto coletor; por sua vez a isoforma $y b$ foi identificada apenas no ramo ascendente medular da alça de Henle e a CHIF foi identificada no ducto coletor, principalmente nas células principais e em porções medulares mais profundas (PihakaskiMaunsbach et al., 2006). Vale destacar que neste mesmo estudo foi demonstrado que estas isoformas não são reguladas por depleção de sódio na dieta, apesar da redução marcante da excreção de sódio, mostrando que a composição de eletrólitos na urina deve ser primariamente regulada por outros sistemas de transporte de sódio (Pihakaski-Maunsbach et al., 2006).

\subsection{Modelo de hipertensão dependente de ouabaína}

Foi no início da década de 90 que os estudos começaram a avaliar os efeitos do tratamento crônico com ouabaína na indução de hipertensão arterial (Yuan et al., 1993) e, a partir desta data vários trabalhos demonstraram que esse tratamento induzia hipertensão arterial em ratos (Huang et al., 1994; Manunta et al., 1994; Kurashina et al., 1996; Kimura et al., 2000; Rossoni et al., 2002a,b, 2006; Kent et al., 2004; Xavier et al., 2004a,b,c; Cheung et al., 2006; Briones et al., 2006; Wenceslau, 2007; Aras-López et al., 2008; Cao et al., 2009; Zhang et al., 2009).

Manunta et al. (1994) começaram a caracterizar o modelo de hipertensão induzida pelo tratamento com ouabaína. Estes pesquisadores demonstraram que esta hipertensão era acompanhada de aumento dos níveis de ouabaína no plasma (1 a 10 nM), nos rins, no hipotálamo e na pituitária anterior. No mesmo ano Huang et al. (1994) observaram que a administração de ouabaína, durante 10 a 14 dias elevava a pressão arterial média de ratos normotensos e que esta resposta devia-se a uma ação da ouabaína sobre o sistema nervoso central. Confirmando esta hipótese, Veerasinghan e Leenen (1999) e Huang e Leenen (1999), demonstraram que parte da hipertensão induzida pelo tratamento crônico com ouabaína estava associada com a ativação do sistema nervoso simpático e prejuízo da atividade barorreflexa, e que este efeito devia-se a uma ativação do sistema reninaangiotensina cerebral (Zhang e Leenen, 2001; Huang et al., 2001). Além do mais, 
esse mesmo grupo demonstrou que após duas semanas de tratamento com ouabaína existe uma elevação de $\pm 15 \mathrm{mmHg}$ nos valores de pressão arterial, a qual está associada a redução na atividade da renina plasmática, assim como, das concentrações plasmáticas de angiotensina I (Ang I) e angiotensina II (Ang II) e a um aumento expressivo nas concentrações hipotalâmicas de Ang II (Cheung et al., 2006). Esses mesmos autores também observaram que havia uma redução na densidade dos receptores $\mathrm{AT}_{1}$ e da enzima conversora de angiotensina no tecido renal dos animais tratados com ouabaína (Cheung et al., 2006).

Além das implicações centrais do tratamento com ouabaína, Rossoni et al. (2006) demonstraram que o tratamento crônico com ouabaína em ratos, por 5 semanas, promove aumento da força de contração do músculo papilar e aumento da atividade da ATPase miosínica no coração de ratos. Estes fatores em conjunto levam a um aumento do efeito inotrópico e lusitrópico positivo medido por cateterismo cardíaco em ratos acordados, ou seja, promove um aumento na contratilidade cardíaca e da velocidade de relaxamento do ventrículo esquerdo de ratos, sendo este um fator importante para determinar um possível aumento no débito cardíaco e, conseqüentemente, na pressão arterial. Jiang et al. (2007) também demonstraram alterações na estrutura e função cardíaca em ratos após o tratamento durante 4 semanas com ouabaína. Estes pesquisadores observaram que o tratamento crônico com ouabaína em ratos promoveu hipertrofia do ventrículo esquerdo, deterioração da ultraestrutura do miocárdio e remodelamento da matriz extracelular, ao passo que piorou a função sistólica e diastólica. Os efeitos da ouabaína citados acima ocorreram antes da elevação da pressão arterial, indicando que a ouabaína pode prejudicar a estrutura e função cardíaca em ratos tratados por 4 semanas independentemente dos valores de pressão arterial (Jiang et al., 2007). Além do mais, também foi demonstrado que a hipertensão induzida por ouabaína vem acompanhada de diferenças regionais na reatividade vascular (Cargnelli et al., 2000; Kimura et al., 2000; Rossoni et al., 2002a,b; Xavier et al., 2004a,b,c; Briones et al., 2006; Wenceslau, 2007; Aras-López, 2008; Cao et al., 2009).

Rossoni et al. (2002a) demonstraram que o tratamento por cinco semanas com ouabaína induz uma elevação significativa da pressão arterial em ratos Wistar, associado à alterações na reatividade vascular à fenilefrina e na atividade e expressão da bomba de sódio e potássio na dependência do leito vascular estudado. Assim, em aortas e artérias mesentéricas superiores foram observadas 
redução da resposta vasoconstritora à fenilefrina, enquanto em anéis de artéria caudal nenhuma alteração foi encontrada (Rossoni et al., 2002a). Já em anéis de artéria renal, Kimura et al. (2000) demonstraram que a hipertensão por ouabaína durante 5 semanas era acompanhada de aumento da resposta contrátil à fenilefrina e ao KCl. Corroborando os resultados de Kimura et al. (2000), Di Filippo et al. (2003) demonstraram que o efeito hipertensor da ouabaína está associado com redução do fluxo sanguíneo renal. Além do mais, recentemente, Cao et al. (2009) demonstraram que o tratamento crônico com ouabaína por 5 semanas promove disfunção endotelial na "vasa recta" de rins de ratos. Estes resultados sugerem que a exposição crônica à ouabaína poderia promover uma redução do fluxo sanguíneo medular, geralmente associado com retenção de sódio e hipertensão (Cao et al., 2009).

O grupo da Dra. Rossoni foi o primeiro a demonstrar que as alterações vasculares também estão na dependência do tempo de tratamento. Neste sentido, Wenceslau (2007) observou que o tratamento com ouabaína durante 20 semanas foi capaz de desenvolver hipertensão de similar magnitude à observada no tratamento por 5 semanas; porém a função vascular nas artérias mesentéricas de resistência foi modulada de maneira distinta. Assim, após 5 semanas de tratamento com ouabaína, não foram observadas alterações significativas na resposta contrátil à noradrenalina, assim como demonstrado por Xavier et al. (2004b); enquanto que após 20 semanas de tratamento com esse glicosídeo, a contração à noradrenalina foi aumentada. Esse aumento da resposta à noradrenalina estava associado a uma perda do componente nitrérgico, aumento do ânion superóxido e aumento da síntese e/ou liberação de tromboxano $\mathrm{A}_{2}$ e/ou prostaglandina $\mathrm{H}_{2}$ via ativação da enzima ciclooxigenase-2 (COX-2), além de redução da contribuição do fator hiperpolarizante derivado do endotélio. Dessa forma, enquanto que no tratamento durante 5 semanas as alterações funcionais não parecem ser mecanismos contribuintes para o aumento da resistência vascular periférica, após 20 semanas houve um aumento da reatividade vascular, que é favorável à manutenção da elevada pressão arterial neste modelo de hipertensão (Wenceslau, 2007).

Como citado anteriormente, o tratamento com ouabaína por 2 semanas promove aumento na atividade simpática, sendo que esta avaliação foi realizada medindo a atividade no nervo renal (Huang e Leenen, 1999). Nesse sentido, tem-se que no modelo de hipertensão induzido por ouabaína a atividade eferente renal 
poderia contribuir de maneira significativa para o processo hipertensivo visto que a ativação simpática renal é responsável por vários mecanismos que contribuem para a hipertensão, tais como: aumento na resistência vascular renal, liberação de renina e retenção de sódio (Katholi, 1983).

Além dos componentes neurais, cardíacos e vasculares, Kurashina e colaboradores (1996) demonstraram que o tratamento crônico com ouabaína também induz alterações na função renal, as quais podem contribuir para o aumento da pressão arterial observada neste modelo experimental. Neste trabalho foi demonstrado que ratos tratados com ouabaína durante 6 semanas apresentam uma redução do fluxo sanguíneo renal e da taxa de filtração glomerular em relação ao animal controle quando submetidos à mesma pressão de perfusão renal. Além do mais, estes pesquisadores demonstraram que os ratos tratados com ouabaína não foram capazes de manter o fluxo sanguíneo renal e a taxa de filtração glomerular quando a pressão de perfusão renal foi reduzida, ou seja, o tratamento com ouabaína prejudica a capacidade de auto-regulação do fluxo sanguíneo renal e da taxa de filtração glomerular (Kurashina et al., 1996). Este estudo também avaliou a excreção de sódio urinário, a qual foi menor nos ratos tratados com ouabaína quando submetidos à mesma pressão de perfusão renal que os animais controle. Assim, estas alterações na função renal poderiam contribuir para gênese e/ou manutenção da pressão arterial elevada observada após a administração crônica de ouabaína em ratos (Kurashina et al., 1996).

Em 2009, Zhang e colaboradores demonstraram que a hipertensão induzida por ouabaína era acompanhada de mudanças na função renal. Esses pesquisadores demonstraram que após 5 semanas de tratamento com ouabaína ocorria redução significativa da fração de excreção de sódio, porém o ritmo de filtração glomerular permanecia normal. Sendo assim, esses resultados sugerem que o tratamento crônico com ouabaína contribuiria para a retenção de sódio e, consequentemente, aumento do volume do fluido extracelular.

Além dos efeitos da ouabaína na função renal, sabe-se que ela pode induzir mecanismos regulatórios importantes sobre a expressão gênica, protéica, atividade e mesmo na redistribuição da $\mathrm{Na}^{+} \mathrm{K}^{+}$-ATPase em cultura de células de túbulos renais. Nesse sentido, Muto et al. (2000) demonstraram que em cultura de células epiteliais renais normais (NRK), tratadas por 24 horas com ouabaína $(0,1$ a $1 \mathrm{mM})$, ocorre aumento da concentração intracelular de sódio, e que este aumento é 
responsável pela indução da expressão gênica e protéica da $\mathrm{Na}^{+} \mathrm{K}^{+}$-ATPase. Porém, nem alterações sobre a concentração intracelular de $\mathrm{Ca}^{2+}$ nem $\mathrm{opH}$ intracelular parecem ser os fatores responsáveis por essas modificações (Muto et al., 2000).

Além disso, Liu et al. (2002) demonstraram que a ouabaína age diferentemente em linhagens de células de túbulos renais. Estes pesquisadores observaram que em cultura de células LLC-PK1, derivadas de células de túbulos proximais de rins de porcos, a ouabaína induz redução da atividade da $\mathrm{Na}^{+} \mathrm{K}^{+}$ATPase. Entretanto, em células MDCK, derivadas de células tubulares renais distais de cão, a ouabaína não modifica a atividade da bomba de sódio e potássio (Liu et al., 2002). Estes pesquisadores sugerem que os mecanismos envolvidos no ajuste distal de sódio estão intactos e sensíveis ao SRAA e ao peptídeo atrial natriurético, embora o ajuste de sódio nos túbulos proximais seja substancialmente alterado (Liu et al., 2002).

Buscando identificar outros possíveis mecanismos através dos quais a ouabaína poderia regular o transporte de sódio ao longo do néfron, Liu et al. demonstraram, em células LLC-PK1, que a ouabaína induz endocitose da $\mathrm{Na}^{+} \mathrm{K}^{+}$ATPase, sendo que este processo é dependente de clatrina (Liu et al., 2004) e caveolina-1 (Liu et al., 2005), e que o mesmo é parte ou conseqüência direta da transdução de sinal através da $\mathrm{Na}^{+} \mathrm{K}^{+}$-ATPase (Liu et al., 2005).

No entanto, apesar do fluxo sanguíneo renal estar reduzido nos animais tratados por 5 semanas com ouabaína e das evidências sobre a ativação aguda das cascatas de sinalização a partir da $\mathrm{Na}^{+} \mathrm{K}^{+}$-ATPase, pouco se sabe sobre o papel dos rins no processo hipertensivo induzido por ouabaína; e sabendo-se da importância dos rins na regulação da pressão arterial, seria de grande relevância para o entendimento do processo de gênese e manutenção da pressão arterial estudar mais profundamente os processos renais associados a este modelo de hipertensão arterial. Nesse sentido, o estudo de Wensceslau (2007) demonstrando que esse é um modelo de hipertensão arterial leve, sem modificações na pressão arterial nos animais tratados com ouabaína por 5 ou 20 semanas, mas com aumento significativo na reatividade vascular em artérias de resistência contribuiu para o interesse em investigar se o tratamento com ouabaína poderia promover alterações na função renal dependentes do tempo a qual poderia contribuir para a manutenção dos níveis de pressão arterial nesse modelo de hipertensão. 
Desta forma, o objetivo deste estudo foi analisar possíveis alterações na função renal em animais hipertensos após o tratamento com ouabaína durante 5 e 20 semanas, assim como os possíveis mecanismos envolvidos. 


\section{CONCLUSÃO}

O presente trabalho investigou a função renal no processo de gênese e manutenção da hipertensão arterial induzida pelo tratamento crônico com ouabaína. Os resultados obtidos no presente estudo mostram que o tratamento crônico com ouabaína por 5 e 20 semanas induz o desenvolvimento de hipertensão, como previamente demonstrado, acompanhado de aumento na ingestão hídrica, no fluxo urinário e na expressão protéica da isoforma $\alpha_{1}$ da $\mathrm{Na}^{+} \mathrm{K}^{+}$ATPase no tecido renal. Porém, não altera de forma significativa a função renal desses ratos. Sendo assim, pode-se sugerir que os rins parecem não contribuir para a manutenção da hipertensão arterial nesse modelo. 


\section{REFERÊNCIAS}

Abrahamsen CT, Barone FC, Campbell WGJr, Nelson AH, Contino LC, Pullen MA, Grygielko ET, Edwards RM,Laping NJ, Brooks DP. The angiotensin type 1 receptor antagonist, eprosartan, attenuates the progression of renal disease in spontaneously hypertensive stroke-prone rats with accelerated hypertension. J Pharmacol Exp Ther. 2002;301(1):21-8.

Abramowitz J, Dai C, Hirschi KK, Dmitrieva RI, Doris PA, Liu L, Allen JC. Ouabainand marinobufagenin-induced proliferation of human umbilical vein smooth muscle cells and a rat vascular smooth muscle cell line, A7r5. Circulation. 2003; 108(24):3048-53.

Aderounmu AF, Salako LA. Abnormal cation composition and transport in erythrocytes from hypertensive patients. Eur J Clin Invest. 1979;9(5):369-75.

Allcock GH, Venema RC, Pollock DM. ETA receptor blockade attenuates the hypertension but not renal dysfunction in DOCA-salt rats. Am J Physiol. 1998;275(1 Pt 2):R245-52.

Aras-López R, Blanco-Rivero J, Hernanz R, Briones AM, Rossoni LV, Ferrer M, Salaices M, Balfagón G. Chronic ouabain treatment increases the contribution of nitric oxide to endothelium-dependent relaxation. J Physiol Biochem. 2008; 64(2):115-25.

Arendshorst WJ, Beierwaltes WH. Renal tubular reabsorption in spontaneously hypertensive rats. Am J Physiol Renal Physiol. 1979; 237(1):F38-47.

Argento NB, Hamilton BP, Valente WA, Hamlyn JM. Increased circulating levels of a ouabain-like compound in hypothyroid hypertension. Hypertension. 1991;18:425.

Aydemir-Koksoy A, Abramowitz J, Allen JC. Ouabain-induced signaling and vascular smooth muscle cell proliferation. J Biol Chem. 2001; 276(49):46605-11.

Beierwaltes WH, Arendshorst WJ, Klemmer PJ. Electrolyte and water balance in young spontaneously hypertensive rats. Hypertension. 1982;4(6):908-15.

Bello-Reuss E, Trevino DL, Gottschalk CW. Effect of renal sympathetic nerve stimulation on proximal water and sodium reabsorption. J Clin Invest. 1976;57:11041107.

Bianchi G, Tripodi G, Casari G, Salardi S, Barber BR, Garcia R, Leoni P, Torielli L, Cusi D, Ferrandi M, Pinna LA, Baralle FE, Ferrari P. Two point mutations within the adducin genes are involved in blood pressure variation. Proc Natl Acad Sci U S A. 1994; 91(9):3999-4003.

\footnotetext{
* De acordo com:

International Committee of Medical Journal Editors. Uniform requirements for manuscripts submitted to Biomedical Journal: sample references. Available from: http://www.icmje.org [2007 May 22].
} 
Bianchi G. Genetic variations of tubular sodium reabsorption leading to "primary" hypertension: from gene polymorphism to clinical symptoms. Am J Physiol Regul Integr Comp Physiol. 2005;289(6):R1536-49.

Blanco G, Mercer, RW. Isozymes of the Na-K-ATPase: heterogeneity in structure, diversity in function. Am J Physiol. 1998;275: F633-F650.

Blaustein MP. Sodium ions, calcium ions, blood pressure regulation, and hypertension: a reassessment and a hypothesis. Am J Physiol. 1977;232(5):C16573.

Blaustein MP. Physiological effects of endogenous ouabain: control of intra-celular $\mathrm{Ca}^{2+}$ stores and cell responsiveness. Am J Physiol. 1993;264:C1367-C1387.

Blaustein MP. Endogenous ouabain: physiological activity and pathophysiological implications. Clin Investig. 1994;72(9):706-7.

Blaustein MP, Juhaszova M, Golovina VA. The cellular mechanism of action of cardiotonic steroids: a new hypothesis. Clin Exp Hypertens. 1998;20(5-6):691-703.

Boron WF, Boulpaep EL. Medical Physiology. $2^{\text {nd }}$. ed. Philadelphia: Saunders Elsevier; 2009.

Bova S, Blaustein MP, Ludens JH, Harris DW, Ducharme DW, Hamlyn JM. Effects of an endogenous ouabainlike compound on heart and aorta. Hypertension. 1991;17: 944-950.

Briones AM, Xavier FE, Arribas SM, Gonzalez MC, Rossoni LV, Alonso MJ, Salaices $M$. Alterations in structure and mechanics of resistance arteries from ouabain induced hypertensive rats. Am J Physiol. 2006;291: H193-H201.

Buckalew VM Jr, Martinez FJ, Green WE. The effect of dialysates and ultrafiltrates of plasma of saline-loaded dogs on toad bladder sodium transport. J Clin Invest. 1970;49(5):926-35.

Cao C, Payne K, Lee-Kwon W, Zhang Z, Lim SW, Hamlyn J, Blaustein MP, Kwon $\mathrm{HM}$, Pallone TL. Chronic ouabain treatment induces vasa recta endothelial dysfunction in the rat. Am J Physiol Renal Physiol. 2009; 296(1):F98-F106.

Cargnelli G, Trevisi L, Debetto P, Luciani S, Bova S. Effect of long-term ouabain treatment on contractile responses of rat aortae. J Cardiovasc Pharmacol. 2000;35:538-42.

Carretero MD, Oparil MD. Essencial Hypertension. Part I: Definition and Etiology. Circulation. 2000;101:329-35.

Cheung WJ, Kent MAH, El-Shaha E, Wang H, Tan J, White R, Leenen FHH. Central and peripheral renin-angiotensin systems in ouabain-induced hypertension. Am J Physiol Heart Circ Physiol. 2006;291: H624-H630. 
Chueh SC, Guh JH, Chen J, Lai MK, Teng CM. Dual effects of ouabain on the regulation of proliferation and apoptosis in human prostatic smooth muscle cells. J Urol. 2001;166(1):347-53.

Coleman TG, Guyton AC. Hypertension caused by salt loading in the dog. Circulation. 1969;25: 153-60.

Cortes VF, Veiga-Lopes FE, Barrabin H, Alves-Ferreira M, Fontes CF. The gamma subunit of $\mathrm{Na}+, \mathrm{K}+-\mathrm{ATPase}$ : role on ATPase activity and regulatory phosphorylation by PKA. Int J Biochem Cell Biol. 2006;38(11):1901-13.

Dahl LK, Knudsen KD, Iwai J. Humoral transmission of hypertension: evidence from parabiosis. Circ Res. 1969;24(5):Suppl:21-33.

de Wardener HE, Mills IH, Clapham WF, Hayter CJ. Studies on the efferent mechanism of the sodium diuresis with follows administration of intravenous saline in dog. Clin Sci. 1961;21:249-58.

de Wardener HE, Clarkson EM. Concept of natriuretic hormone. Physiol Rev. 1985;65: 658-759.

Di Filippo C, Filippelli A, Rinaldi B, Piegari E, Esposito F, Rossi F, D'amico M. Chronic peripheral ouabain treatment affects the brain endothelin system of rats. $J$ Hypertens. 2003;21:747-53.

Dilley JR, Stier CT Jr, Arendshorst WJ. Abnormalities in glomerular function in rats developing spontaneous hypertension. Am J Physiol. 1984;246(1 Pt 2):F12-20.

V Diretrizes Brasileiras de Hipertensão Arterial. São Paulo: Sociedade Brasileira de Cardiologia; 2006.

Doursout MF, Chelly JE, Liang YY, Buckley JP. The ouabain-dependent $\mathrm{Na}(+)-\mathrm{K}+$ pump and the brain renin-angiotensin system. Clin Exp Hypertens. 1992;14(3):393411.

Edmondson RP, Thomas RD, Hilton PJ, Patrick J, Jones NF. Abnormal leucocyte composition and sodium transport in essential hypertension. Lancet. 1975;1(7914):1003-5.

Eiam-Ong S, Hilden SA, Johns CA, Madias NE. Stimulation of basolateral $\mathrm{Na}(+)-$ HCO3- cotransporter by angiotensin II in rabbit renal cortex. Am J Physiol Renal Physiol. 1993;265(2 Pt 2):F195-203.

Elks CM, Mariappan N, Haque M, Guggilam A, Majid DS, Francis J. Chronic NF\{kappa\}B blockade reduces cytosolic and mitochondrial oxidative stress and attenuates renal injury and hypertension in SHR. Am J Physiol Renal Physiol. 2009;296(2):F298-305.

Elmarakby AA, Quigley JE, Imig JD, Pollock JS, Pollock DM. TNF-alpha inhibition reduces renal injury in DOCA-salt hypertensive rats. Am J Physiol Regul Integr Comp Physiol. 2008;294(1):R76-83. 
Féraille $E$, Doucet A. Sodium-potassium-adenosinetriphosphatase-dependent sodium transport in the kidney: hormonal control. Physiol Rev. 2001;81(1):345-418.

Ferrandi M, Tripodi G, Salardi S, Florio M, Modica R, Barassi P, Parenti P, Shainskaya A, Karlish S, Bianchi G, Ferrari P. Renal Na,K-ATPase in genetic hypertension. Hypertension. 1996;28(6):1018-25.

Ferrandi M, Manunta P, Rivera R, Bianchi G, Ferrari P. Role of the ouabain-like factor and $\mathrm{Na}-\mathrm{K}$ pump in rat and human genetic hypertension. Clin Exp Hypertens. 1998;20(5-6):629-39.

Ferrandi M, Salardi S, Tripodi G, Barassi P, Rivera R, Manunta P, Goldshleger R, Ferrari $P$, Bianchi $G$, Karlish SJ. Evidence for an interaction between adducin and $\mathrm{Na}(+)-\mathrm{K}(+)-A T P a s e:$ relation to genetic hypertension. Am J Physiol. 1999;277(4 Pt 2):H1338-49.

Ferrandi M, Molinari I, Barassi P, Minotti E, Bianchi G, Ferrari P. Organ hypertrophic signaling within caveolae membrane subdomains triggered by ouabain and antagonized by PST 2238. J Biol Chem. 2004;279(32):33306-14.

Ferrari $P$, Torielli L, Ferrandi M, Padoani G, Duzzi L, Florio M, Conti F, Melloni $P$, Vesci L, Corsico N, Bianchi G. PST2238: a new antihypertensive compound that antagonizes the long-term pressor effect of ouabain. J Pharmacol Exp Ther. 1998;285(1):83-94.

Garg LC, Narang N, McArdle S. Na-K-ATPase in nephron segments of rats developing spontaneous hypertension. Am J Physiol. 1985;249(6 Pt 2):F863-9.

Garvin JL. Angiotensin stimulates bicarbonate transport and $\mathrm{Na}+\mathrm{K}+$ ATPase in rat proximal straight tubules. J Am Soc Nephrol. 1991;1(10):1146-52.

Geering $\mathrm{K}$. The functional role of the beta-subunit in the maturation and intracellular transport of Na,K-ATPase. FEBS Lett. 1991;285(2):189-93.

Glynn IM. Annual review prize lecture. 'All hands to the sodium pump'. J Physiol. 1993;462:1-30.

Goldblatt H, Lynch J, Ranzal RF, Summerville WW. Studies on experimental hypertension. I. The production of persistent elevation of systolic blood pressure by means of renal ischemia. J Exp Med. 1934;59:347-79.

Guyenet PG. The sympathetic control of blood pressure. Nat Rev Neurosci. 2006;7(5):335-46.

Guyton AC, Coleman TG. Long-term regulation of the circulation: interrelationships with body fluid volumes. Physical Bases of Circulatory Transport Regulation and Exchange. Philadelphia, PA: Saunders; 1967.

Haddy FJ, Overbeck HW. The role of humoral agents in volume expanded hypertension. Life Sci. 1976;19(7):935-47. 
Hamlyn JM, Ringel R, Schaeffer J, Levinson PD, Hamilton BP, Kowarski AA, Blaustein MP. A circulating inhibitor of $\left(\mathrm{Na}^{+}, \mathrm{K}^{+}\right)$-ATPase associated with essential hypertension. Nature. 1982;300: 650-52.

Hamlyn JM, Blaustein MP, Bova S, DuCharme DW, Harris DW, Mandel F, Mathews WR, Ludens JH. Identification and characterization of a ouabain-like compound from human plasma. Proc Natl Acad Sci. 1991; 88(14):6259-63.

Hamlyn JM, Hamilton BP, Manunta P. Endogenous ouabain, sodium balance and blood pressure: a review and a hypothesis. J Hypertens. 1996; 14(2):151-67.

Haas M, Askari A, Xie Z. Involvement of Src and epidermal growth factor receptor in the signal-transducing function of $\mathrm{Na}+/ \mathrm{K}_{+}-\mathrm{ATPase} \mathrm{J}$ Biol Chem. 2000;275(36):27832-7.

Himmelstein SI, Klotman PE. The role of thromboxane in two-kidney, one-clip Goldblatt hypertension in rats. Am J Physiol. 1989;257(2 Pt 2):F190-6.

Horowitz A, Menice CB, Laporte R, Morgan KG. Mechanisms of smooth muscle contraction. Physiol Rev. 1996; 76(4):967-1003.

Huang BS, Huang X, Harmsen E, Leenen FHH. Chronic central versus peripheral ouabain, blood pressure, and sympathetic activity in rats. Hypertension. 1994;23(Part 2):1087-90.

Huang BS, Leenen FHH. Brain renin-angiotensin system and ouabain-induced sympathetic hyperactivity and hypertension in wistar rats. Hypertension. 1999;34:107-12.

Huang BS, Ganten D, Leenen FHH. Responses to central $\mathrm{Na}^{+}$and ouabain are attenuated in transgenic rats deficient in brain angiotensinogen. Hypertension. 2001;37(2 Part 2):683-6.

Jadhav A, Torlakovic E, Ndisang JF. Hemin therapy attenuates kidney injury in deoxycorticosterone acetate-salt hypertensive rats. Am J Physiol Renal Physiol. 2009;296(3):F521-34.

Jiang X, Ren Y, Lu Z. Ouabain induces cardiac remodeling in rats independent of blood pressure. Acta Pharmacol Sin. 2007;28(3):344-52.

Judy WV, Watanabe AM, Henry DP, Besch HR Jr, Murphy WR, Hockel GM. Sympathetic nerve activity: role in regulation of blood pressure in the spontaenously hypertensive rat. Circ Res. 1976;38(6 Suppl 2):21-9.

Judy WV, Watanabe AM, Murphy WR, Aprison BS, Yu PL. Sympathetic nerve activity and blood pressure in normotensive backcross rats genetically related to the spontaneously hypertensive rat. Hypertension. 1979;1(6):598-604.

Kaplan NM. Clinical Hypertension. 9 ed. Philadelphia: Williams \& Wilkins; 2006. p. 124. 
Kassab S, Hamdy H, AbdulGhaffar T, Granger JP. Effects of endothelin-A receptor antagonism on bilateral renal function in renovascular hypertensive rats. Fundam Clin Pharmacol. 2001;15(6):379-85.

Katholi RE. Renal nerves in the pathogenesis of hypertension in experimental animals and humans. Am J Physiol. 1983;245(1):F1-14.

Kearney PM, Whelton M, Reynolds K, Muntner P, Whelton PK, He J. Global burden of hypertension: analysis of worldwide data. Lancet. 2005;365(9455):217-23.

Kent MA, Huang BS, Van Huysse JW, Leenen FH. Brain $\mathrm{Na}^{+}, \mathrm{K}^{+}$-ATPase isozyme activity and protein expression in ouabain-induced hypertension. Brain Res. 2004;1018(2):171-80.

Khundmiri SJ, Metzler MA, Ameen M, Amin V, Rane MJ, Delamere NA. Ouabain induces cell proliferation through calcium-dependent phosphorylation of Akt (protein kinase B) in opossum kidney proximal tubule cells. Am J Physiol Cell Physiol. 2006;291(6):C1247-57.

Kim SW, Wang W, Kwon TH, Knepper MA, Frøkiaer J, Nielsen S. Increased expression of ENaC subunits and increased apical targeting of AQP2 in the kidneys of spontaneously hypertensive rats. Am J Physiol Renal Physiol. 2005;289(5):F95768.

Kimura K, Manunta P, Hamilton BP, Hamlyn JM. Different effects of in vivo ouabain and digoxin on renal artery function and blood pressure in the rat. Hypertens Res. 2000;23(Suppl):67-76.

Kobori H, Ozawa Y, Suzaki Y, Nishiyama A. Enhanced intrarenal angiotensinogen contributes to early renal injury in spontaneously hypertensive rats. J Am Soc Nephrol. 2005;16(7):2073-80.

Kobori H, Nangaku M, Navar LG, Nishiyama A. (2007). The intrarenal reninangiotensin system: from physiology to the pathobiology of hypertension and kidney disease. Pharmacol Rev. 2007;59(3):251-87.

Kopf D, Waldherr R, Rettig R. Source of kidney determines blood pressure in young renal transplanted rats. Am J Physiol Renal Physiol. 1993;265(1 Pt 2):F104-1.

Kohzuki M, Abe K, Yasujima M, Kasai Y, Hiwatari M, Kanazawa M, Sato M, Omata $\mathrm{K}$, Kudo K, Takeuchi K, Yoshinaga K. Blood pressure and renal responses to synthetic rat atrial natriuretic factor in deoxycorticosterone acetate-salt hypertension. Tohoku J Exp Med. 1989;57(4):301-11.

Kometiani P, Tian J, Li J, Nabih Z, Gick G, Xie Z. Regulation of Na/K-ATPase beta1subunit gene expression by ouabain and other hypertrophic stimuli in neonatal rat cardiac myocytes. Mol Cell Biochem. 2000;215(1-2):65-72.

Kramer HJ, Gonick HC, Paul WC, Lu E. Third factor: inhibitor of Na-K-ATPase? In: $4^{\text {th }}$ International Congress of Nephrology; Stockholm; 1969. Abstract; p. 373. 
Kurashina T, Kirchner KA, Granger JP, Patel AR. Chronic sodium-potassium-ATPase inhibition with ouabain impairs renal haemodynamics and pressure natriuresis in the rat. Clin Sci. 1996;91:497-502.

Lanzani C, Citterio L, Jankaricova M, Sciarrone MT, Barlassina C, Fattori S, Messaggio E, Serio CD, Zagato L, Cusi D, Hamlyn JM, Stella A, Bianchi G, Manunta $P$. Role of the adducin family genes in human essential hypertension. J Hypertens. $2005 ; 23(3): 543-9$.

Laredo J, Shah JR, Lu ZR, Hamilton BP, Hamlyn JM. (1997). Angiotensin II stimulates secretion of endogenous ouabain from bovine adrenocortical cells via angiotensin type 2 receptor. Hypertension. 1997;29 (Part2):401-7.

Leenen $\mathrm{FH}$, de Jong $\mathrm{W}$. Plasma renin activity and renal blood flow in renal hypertensive rats with different blood pressure levels. J Endocrinol. 1971;48(4):IxxV+.

Li M, Martin A, Wen C, Turner SW, Lewis LK, Whitworth JA. Long-term ouabain administration does not alter blood pressure in conscious Sprague-Dawley rats. Clin Exp Pharmacol Physiol. 1995;22(12):919-23.

Lindzen M, Gottschalk KE, Füzesi M, Garty H, Karlish SJ. Structural interactions between FXYD proteins and $\mathrm{Na}+, \mathrm{K}+-\mathrm{ATPase}$ alpha/beta/FXYD subunit stoichiometry and cross-linking. J Biol Chem. 2005;280(18):18291-301.

Lingrel JB. Na,K-ATPase: isoform structure, function, and expression. Journal of Bioenergetics and Biomembranes. 1992;24(3):263-70.

Liu FY, Cogan MG. Angiotensin II stimulation of hydrogen ion secretion in the rat early proximal tubule. Modes of action, mechanism, and kinetics. J Clin Invest. 1988;82(2): 601-7.

Liu J, Tian J, Haas M, Shapiro JI, Askari A, Xie Z. Ouabain interaction with cardiac $\mathrm{Na}+/ \mathrm{K}+-\mathrm{ATPase}$ initiates signal cascades independent of changes in intracellular $\mathrm{Na}+$ and Ca2+ concentrations. J Biol Chem. 2000;275(36):27838-44.

Liu J, Periyasamy SM, Gunning W, Fedorova OV, Bagrov AY, Malhorta D, Xie Z, Shapiro Jl. Effects of cardiac glycosides on sodium pump expression and function in LLC-PK1 and MDCK cells. Kidney Int. 2002;62(6):2118-25.

Liu J, Kesiry R, Periyasamy SM, Malhorta D, Xie Z, Shapiro Jl. Ouabain induces endocytosis of plasmalemmal $\mathrm{Na} / \mathrm{K}$-ATPase in LLC-PK1 cells by a clathrindependent mechanism. Kidney Int. 2004;66(1):227-41.

Liu J, Liang M, Liu L, Malhorta D, Xie Z, Shapiro Jl. Ouabain-induced endocytosis of the plasmalemmal $\mathrm{Na} / \mathrm{K}-\mathrm{ATP}$ ase in LLC-PK1 cells requires caveolin-1. Kidney Int. $2005 ; 67(5): 1844-54$

Loreaux EL, Kaul B, Lorenz JN, Lingrel JB. Ouabain-Sensitive alpha1 Na,K-ATPase enhances natriuretic response to saline load. J Am Soc Nephrol. 2008;19(10):1947-54.

Ludens JH, Clark MA, Robinson FG, Ducharme DW. Rat adrenal cortex is a source of a circulanting ouabain-like compound. Hypertension. 1992; 19: 721-4. 
MacGregor GA, Fenton S, Alaghband-Zadeh J, Markandu N, Roulston JE, de Wardener HE. Evidence for a raised concentration of a circulating sodium transport inhibitor in essential hypertension. Br Med J (Clin Res Ed). 1981; 21;283(6303):13557.

Manunta P, Evans G, Hamilton BP, Gann D, Resau J, Hamlyn JM. A new syndrome with elevated plasma ouabain and hypertension secondary to an adrenocortical tumor. J Hypertens. 1992;10 (Suppl. 4):S27.

Manunta P, Rogowski AC, Hamilton BP, Hamlyn JM. Ouabain-induced hypertension in the rat: relationships among plasma and tissue ouabain and blood pressure. $J$ Hypertens. 1994;12:549-60.

Manunta P, Stella P, Rivera R, Ciurlino D, Cusi D, Ferrandi M, Hamlyn JM, Bianchi G. Left ventricular mass, stroke volume, and ouabain-like factor in essencial hypertension. Hypertension. 1999;34:450-6.

Manunta P, Maillard M, Tantardini C, Simonini M, Lanzani C, Citterio L, Stella P, Casamassima N, Burnier M, Hamlyn JM, Bianchi G. Relationships among endogenous ouabain, alpha-adducin polymorphisms and renal sodium handling in primary hypertension. J Hypertens. 2008;26(5):914-20.

Matsumura Y, Hashimoto N, Fujita K, Morimoto S. Ameliorating effect of an endothelin ETA receptor antagonist on renal function of DOCA-salt hypertensive rats. Eur J Pharmacol. 1997;319(1):65-9.

Matsumura Y, Hashimoto N, Taira S, Kuro T, Kitano R, Ohkita M, Opgenorth TJ, Takaoka M. Different contributions of endothelin-A and endothelin-B receptors in the pathogenesis of deoxycorticosterone acetate-salt-induced hypertension in rats. Hypertension. 1999;33(2):759-65.

Mercer RW. Structure of the Na,K-ATPase. Int Rev Cytol. 1993;137C:139-68.

Mitchell KD, Braam B, Navar LG. Hypertensinogenic mechanisms mediated by renal actions of renin-angiotensin system. Hypertension. 1992;19(1 Suppl):I18-27.

Möhring J, Petri M, Möhring B. Salt appetite during the early phase of renal hypertension in rats. Pflugers Arch. 1975a;56(2):153-8.

Möhring J, Möhring B, Näumann H-J, Philippi A, Homsy E, Orth H, Dauda G, Kazda $S$. Salt and water balance and renin activity in renal hypertension of rats. Am J Physiol. 1975b;228(6):1847-55.

Morduchowicz GA, Sheikh-Hamad D, Jo OD, Nord EP, Lee DB, Yanagawa N. Increased $\mathrm{Na}+/ \mathrm{H}+$ antiport activity in the renal brush border membrane of SHR. Kidney Int. 1989;36(4):576-81.

Moreth K, Kuske R, Renner D, Schoner W. Blood pressure in essential hypertension correlates with the concentration of a circulating inhibitor of the sodium pump. Klin Wochenschr. 1986;4(5):239-44. 
Morth JP, Pedersen BP, Toustrup-Jensen MS, Sørensen TL, Petersen J, Andersen JP, Vilsen B, Nissen P. Crystal structure of the sodium-potassium pump. Nature. 2007;450(7172):1043-9.

Mullins LJ, Bailey MA, Mullins JJ. Hypertension, kidneys and transgenics: A fresh perspectives. Physiol Rev. 2006;86(2):709-46.

Muto S, Nemoto J, Okada K, Miyata Y, Kawakami K, Saito T, Asano Y. (2000). Intracellular $\mathrm{Na}^{+}$directly modulates $\mathrm{Na}^{+}, \mathrm{K}^{+}$-ATPase gene expression in normal rat kidney epithelial cells. Kidney Int. 2000;57(4):1617-35.

Naruse K, Naruse M, Tanabe A, Yoshimoto T, Watanabe Y, Kurimoto F, Horiba N, Tamura M, Inagami T, Demura H. Does plasma immunoreactive ouabain originate in adrenal gland? Hypertension. 1994;23(Suppl. I):1102-1105.

Okamoto K, Nosaka S, Yamori Y, Matsumoto M. Participation of neural factor in the pathogenesis of hypertension in the spontaneously hypertensive rat. Jpn Heart J. 1967;8(2):168-80.

Oparil S. The sympathetic nervous system in clinical and experimental hypertension. Kidney Int. 1986;30(3):437-52.

Pamnani M, Huot S, Buggy J, Clough D, Haddy FJ. Demonstration of a humoral inhibitor of the $\mathrm{Na}^{+}-\mathrm{K}^{+}$pump in some models of experimental hypertension. Hypertension. 1981;3(Suppl II):II96-II101.

Pamnani MB, Burris JF, Jemionek JF, Huot SJ, Price M, Freis ED, Haddy FJ. Humoral $\mathrm{Na}+-\mathrm{K}_{+}$pump inhibitory activity in essential hypertension and in normotensive subjects after acute volume expansion. Am $\mathrm{J}$ Hypertens. 1989;2(7):524-31.

Pestel S, Krzykalla V, Weckesser G. Measurement of glomerular filtration rate in the conscious rat. J Pharmacol Toxicol Methods. 2007;56(3):277-89.

Pidgeon GB, Richards AM, Nicholls MG, Charles CJ, Rademaker MT, Lynn KL, Bailey RR, Lewis LK, Yandle TG. Chronic ouabain infusion does not cause hypertension in sheep. Am J Physiol. 1996;270(3 Pt 1):E386-92.

Pihakaski-Maunsbach K, Vorum H, Honoré B, Tokonabe S, Frøkiaer J, Garty H, Karlish SJ, Maunsbach AB. Locations, abundances, and possible functions of FXYD ion transport regulators in rat renal medulla. Am J Physiol Renal Physiol. 2006;291(5):F1033-44.

Pollock DM, Allcock GH, Krishnan A, Dayton BD, Pollock JS. Upregulation of endothelin $B$ receptors in kidneys of DOCA-salt hypertensive rats. Am J Physiol Renal Physiol. 2000a;278(2):F279-86.

Pollock DM, Derebail VK, Yamamoto T, Pollock JS. Combined effects of AT(1) and $\mathrm{ET}(\mathrm{A})$ receptor antagonists, candesartan, and A-127722 in DOCA-salt hypertensive rats. Gen Pharmacol. 2000b; 34(5):337-42. 
Poston L, Sewell RB, Wilkinson SP, Richardson PJ, Williams R, Clarkson EM, MacGregor GA, de Wardener HE. Evidence for a circulating sodium transport inhibitor in essential hypertension. Br Med J (Clin Res Ed). 1981; 282(6267):847-9.

Price EM, Lingrel JB. Structure-function relationships in the Na,K-ATPase alpha subunit: site-directed mutagenesis of glutamine-111 to arginine and asparagine-122 to aspartic acid generates a ouabain-resistant enzyme. Biochemistry. 1988;27(22):8400-8.

Radzialowski FM, Hypertension Resarch: Methods and Models. New York: Marcel Dekker; 1982.

Rembold CM. Regulation of contraction and relaxation in arterial smooth muscle. Hypertension. 1992;20(2):129-37.

Roman RJ, Cowley AW Jr. Abnormal pressure-diuresis-natriuresis response in spontaneously hypertensive rats. Am J Physiol. 1985;248(2 Pt 2):F199-205.

Roman RJ, Kaldunski ML, Mattson DL, Mistry M, Nasjletti A. Influence of eicosanoids on renal function of DOCA-salt hypertensive rats. Hypertension. 1988;12(3):287-94.

Rossi GP, Manunta P, Hamlyn JM, Pavan E, De Toni R, Semplicini A. Immunoreactive endogenous ouabain in primary aldosteronism and essential hypertension: relationship with plasma renin, aldosterone and blood pressure. J Hypertens. 1995;13(10):1181-91.

Rossoni LV, Salaices M, Marín J, Vassallo DV, Alonso MJ. Alterations in the phenylephrine-induced contractions and the vascular expression of $\mathrm{Na}^{+}, \mathrm{K}^{+}$-ATPase in ouabain-induced hypertension. Br J Pharmacol. 2002a;135:771-781.

Rossoni LV, Salaices M, Miguel M, Briones AM, Barker LA, Vassallo DV, Alonso MJ. Ouabain-induced hypertension is accompanied by increases in endothelial vasodilator factors. Am J Physiol. 2002b;283:H2110-H2118.

Rossoni LV, Xavier FE, Moreira CM, Falcochio D, Amanso AM, Tanque CU, Carvalho CR, Vassallo DV. Ouabain-induced hypertension enhances left ventricular contractility in rats. Life Sci. 2006;79:1537-45.

Rostand SG, Lewis D, Watkins JB, Huang WC, Navar LG. Attenuated pressure natriuresis in hypertensive rats. Kidney Int. 1982;21(2):331-8.

Saunders R, Scheiner-Bobis G. Ouabain stimulates endothelin release and expression in human endothelial cells without inhibiting the sodium pump. Eur $\mathrm{J}$ Biochem. 2004; 271(5):1054-62.

Schaeffer JS, Talartschik J, Koch KM, Rogowiski AC, Manunta P, Hamlyn JM. Increased plasma levels of ouabain-like compound in dialysis patients: relationship with interdialytic volume changes. J Am Soc Nephrol. 1991;2(Suppl. 3):348.

Schoner W, Scheiner-Bobis G. Endogenous and exogenous cardiac glycosides: their roles in hypertension, salt metabolism, and cell growth. Am J Physiol Cell Physiol. 2007;293(2):C509-36. 
Sekihara H, Yazaki Y, Kojima T. Ouabain as an amplifier of mineralocorticoidinduced hypertension. Endocrinology. 1992;131(6):3077-82.

Simpson JB, Epstein AN, Camardo JS Jr. Localization of receptors for the dipsogenic action of angiotensin II in the subfornical organ of rat. J Comp Physiol Psychol. 1978;92(4):581-601.

Skou JC, Esmann M. The Na+K+ATPase. J Bioenerg Biomembr. 1992;24:249-61.

Slick GL, Aguilera AJ, Zambraski EJ, DiBona GF, Kaloyanides GJ. Renal neuroadrenergic transmission. Am J Physiol. 1975;229(1):60-5.

Songu-Mize E, Bealer SL, Caldwell W. Effect of AV3V Lesions on development of DOCA-Salt hypertension and vascular $\mathrm{Na}^{+}$-Pump activity. Hypertension. 1982;4:57580.

Sweadner KJ. Isozymes of the $\mathrm{Na}^{+} \mathrm{K}^{+}$-ATPase. Biochim Biophys Acta. 1989;988:185220.

Therien AG, Nestor NB, Ball WJ, Blostein R. Tissue-specific versus isoform-specific differences in cation activation kinetics of the Na,K-ATPase. $J$ Biol Chem. $1996 ; 271(12): 7104-12$

Thorén P, Ricksten SE. Recordings of renal and splanchnic sympathetic nervous activity in normotensive and spontaneously hypertensive rats. Clin Sci (Lond). 1979;57 Suppl 5:197s-199s.

Tripodi G, Citterio L, Kouznetsova T, Lanzani C, Florio M, Modica R, Messaggio E, Hamlyn JM, Zagato L, Bianchi G, Staessen JA, Manunta P. Steroid biosynthesis and renal excretion in human essential hypertension: association with blood pressure and endogenous ouabain. Am J Hypertens. 2009;22(4):357-63.

Véniant M, Heudes D, Clozel JP, Bruneval P, Ménard J. Calcium blockade versus ACE inhibition in clipped and unclipped kidneys of $2 \mathrm{~K}-1 \mathrm{C}$ rats. Kidney Int. $1994 ; 46(2): 421-9$

Veerasinghan SJ, Leenen FHH. Ouabain- and central sodium-induced hypertension depend on the ventral anteroventral third ventricle region. Am J Physiol. 1999;276(1 Pt 2):H63-70.

Wang T, Giebisch G. Effects of angiotensin II on electrolyte transport in the early and late distal tubule in rat kidney. Am J Physiol Renal Physiol. 1996; 271(1 Pt 2):F143-9.

Wang Y, Babánková D, Huang J, Swain GM, Wang DH. Deletion of transient receptor potential vanilloid type 1 receptors exaggerates renal damage in deoxycorticosterone acetate-salt hypertension. Hypertension. 2008; 52(2):264-70.

Welch WJ, Mendonca M, Aslam S, Wilcox CS. Roles of oxidative stress and AT1 receptors in renal hemodynamics and oxygenation in the postclipped $2 \mathrm{~K}, 1 \mathrm{C}$ kidney. Hypertension. 2003; 41(3 Pt 2):692-6. 
Wensceslau CF. Efeito da administração crônica a longo prazo de ouabaína sobre a pressão arterial e a reatividade vascular de artérias mesentéricas de resistência de rato: possíveis mecanismos envolvidos [dissertação]. São Paulo: Instituto de Ciências Biomédicas da Universidade de São Paulo; 2007.

Wenzel UO, Wolf G, Jacob I, Schwegler C, Qasqas A, Amann K, Helmchen U, Stahl RA. Beneficial and adverse renal and vascular effects of the vasopeptidase inhibitor omapatrilat in renovascular hypertensive rats. Nephrol Dial Transplant. 2003;18(10):2005-13.

Winternitz SR, Katholi RE, Oparil S. Role of the renal sympathetic nerves in the development and maintenance of hypertension in the spontaneously hypertensive rat. J Clin Invest. 1980;66(5):971-8.

Wong VY, Laping NJ, Nelson AH, Contino LC, Olson BA, Gygielko E, Campbell WG Jr, Barone F, Brooks DP. Renoprotective effects of carvedilol in hypertensive-stroke prone rats may involve inhibition of TGF beta expression. $\mathrm{Br} J$ Pharmacol. 2001;134(5):977-84.

Xavier FE, Salaices M, Marquez-Rodas I, Alonso MJ, Rossoni LV, Vassallo DV, Balfagón G. Neurogenic nitric oxide release increases in mesenteric arteries from ouabain hypertensive rats. J Hypertens. 2004a;22:949-57.

Xavier FE, Rossoni LV, Alonso MJ, Balfagón G, Vassallo DV, Salaices M. Ouabaininduced hypertension alters the participation of endothelial factors in a-adrenergic responses differently in rat resistance and conductance mesenteric arteries. $\mathrm{Br} \mathrm{J}$ Pharmacol. 2004b;143:215-25.

Xavier FE, Yogi A, Callera GE, Tostes RC, Alvarez Y, Salaices M, Alonso MJ, Rossoni LV. Contribution of the endothelin and renin-angiotensin systems to the vascular changes in rats chronically treated with ouabain. $\mathrm{Br} \mathrm{J}$ Pharmacol. 2004c;143:794-802.

Yasujima M, Abe K, Tanno M, Kohzuki M, Kasai Y, Sato M, Omata K, Takeuchi $\mathrm{K}$, Yoshinaga K, Masugi F, Ogihara T. Effects of ouabain on blood pressure regulation in rats. J Hypertens. 1986;4(5):597-601.

Yuan CM, Manunta P, Hamlyn JM, Chen S, Bohen E, Yeun J, Haddy FJ, Pa mnani MB. Long-term ouabain administration produces hypertension in rats. Hypertension. 1993;22:178-87.

Zatz R. Fisiopatologia Renal. São Paulo: Atheneu; 2002.

Zhang J, Leenen $\mathrm{FHH}$. $\mathrm{AT}_{1}$ receptor blockers prevent sympathetic hyperactivity and hypertension by chronic ouabain and hypertonic saline. Am J Physiol. 2001;280:H1318-H1323.

Zhang Y, Yuan Z, Ge H, Ren Y. Effects of long-term ouabain treatment on blood pressure, sodium excretion, and renal dopamine $\mathrm{D}(1)$ receptor levels in rats. J Comp Physiol B. 2009. [Epub ahead of print]. 